\title{
Research on Current Situation, Problems and Countermeasures of Security Technology of Mining Machinery
}

\author{
Mingqi $\mathrm{Su}^{1, \mathrm{a}}$ \\ ${ }^{1}$ Jiangsu College of Safety Technology, Xuzhou, 221011, China \\ ${ }^{\mathrm{a}}$ email
}

Keywords: Mining machinery, Security technology, Security standards

\begin{abstract}
In recent years, with the rapid development of China's economy, the frequent occurrence of safety accidents of mining machinery has also attracted the attention of the central government and relevant departments. This paper analyzes the present situation of security technology of mining machinery in China, points out the existing problems, and give some suggestions from the perspective of improving detection technology, perfecting security standards and strengthening staff training to provide some references for the relative researchers.
\end{abstract}

\section{Current Situation of Security Technology of Mining Machinery}

Since the beginning of last century, China has attached great importance to the development of the mining machinery industry. Through continuous development, exploration and innovation, the safety of mine machinery has achieved remarkable results. At present, China's AC traction shearer is gradually mature, mine tunneling machine from the early light to medium and heavy, cutting objects from coal to rock. Most of the domestic equipment has the function of on-line detection and real-time monitoring, which greatly improves the safety of the equipment. Our country attaches great importance to safety standards, but also actively formulate a variety of safety standards, the establishment of international standards of safety standards system. At present, due to the difference of mine management mode, the use of mining machinery is also very different. According to the mode of production and management, we can divide them into three categories. The first type is constructed or rebuilt before and after liberation. The operating equipment is relatively backward, and the safety awareness of the staff is weak. They have a lot of security risks, and cannot meet the needs of safety production. Due to the development of production, the new mine basically adopts the large-scale mechanized operation, and realizes the electromechanical integration operation of mining machinery equipment. Because of the high starting point of construction, there are relatively few safety risks in this kind of mine. The third kind is the small mine that distributes in partial villages and towns. As a result of such a large number of mines, widely distributed, generally belong to individual contract management. In pursuit of greater benefits, operators often do not spend huge sums of money on large machinery equipment for mining operations, and most of the equipment used is beyond the service cycle of the equipment. Due to the contract management on personnel selection requirements are relatively low, the overall poor quality, safety assurance measures cannot be timely in place, this kind of enterprise is the existence of security risks in most places, but also the occurrence of safety accidents in most places. As a whole, China's mine safety technology is uneven, and the gap is relatively large.

\section{Problems of Security Technology of Mining Machinery}

Unripe Technology of Detection. The mining machinery operation conditions, easily lead to a variety of security risks, security risks cannot be excluded if timely, equipment operation will cause accidents occurred in the state with hidden dangers. Due to the complexity of mining machinery and equipment and the existence of a large number of unpredictable accidents, the safety inspection technology of mine machinery needs to be improved step by step. Mining machinery and equipment are generally in the alternating state of day and night, and for a long time, under alternating load and 
heavy load, a variety of security risks are likely to occur. If you fail to find safety problems in time, you will indulge in this vicious circle, which has laid a hidden danger for the accident. Although our country has been testing equipment and technology has been constantly updated, the introduction of modern equipment and technology, and enhance its performance in all its aspects. However, the complexity of the mining machinery and the complex working environment form a large number of unpredictable factors, and there are a series of accidents. Overall, the current safety inspection technology of mine machinery still needs further improvement, and improve its performance, especially in reliability and sensitivity, to meet the actual needs of mining machinery. In addition, research in many complex areas is still not deep enough and needs to be improved. For example, some mines need reasonable allocation of air flow, thus diluting the gas flowing out of the coal seam and the mined out area. The air flow configuration work, considering the main factors are: considering the fully mechanized working face in the way, the deformation factors of cross section design, wind tunnel in the mining period.

Imperfect Standards of Safety. At present, the standard for the safety of mining machinery involves many kinds of machinery, such as mine hoist, mine hole drilling machine and so on. It provides an overall manufacturing principle and framework for the manufacturing and use departments. It is in the predetermined range of use, to ensure product safety. However, as far as the varieties of mining machinery products in China are concerned, it has risen to several hundred. The mineral machinery and equipment involved in the existing standards account for a small part of them, which makes it difficult to meet the safety requirements of mining machinery and equipment. As we all know, the basic guarantee of coal mine safety is safety and quality standardization. However, in the current rapid growth of coal demand, the quality standardization work mode can easily lead to people's boredom and relaxation of ideas. In addition, expensive investment, the mine manager in front of the standard quality, schedule, yield, more inclined to the latter two, quality standardization ignored, resulting in a gradual decline in safety and quality standardization, safety accidents occurred for buried hidden trouble. We urgently need to improve the safety standards of mining machinery, and then strictly enforce them. In the mining machinery safety standards already, because it involves more and more aspects, relates to the mine hoist, underground scraper and other dozens of these mechanical safety standards for the use of mechanical design and manufacturing, to provide a guidance to the greatest degree guarantee the safety of the operation, within the scope of however, because the mechanical products of mine, there are hundreds of. Therefore, the existing safety standards have been unable to meet the safety requirements of all mechanical products.

Low Quality of Employees. The operation of mining machinery and equipment depends on the operation of personnel, and the comprehensive quality of mine employees determines the safety degree of mining machinery to a certain extent. Dangerous, difficult mining operations, determine the complexity of employees, low educational level, lack of self-protection awareness and habits of barbaric operation and the safety performance of equipment such as lack of awareness is the key factor causing mining machinery accident. It can be said that the lack of support for the people, for the safety of mining machinery technology to enhance its equipment handling capacity, make it master the safety of machinery and equipment, the operation is very urgent. The dangerous work of mine, and mine machinery practitioners are more complex, some mechanical equipment operating personnel and cultural quality is not high, the safety performance is not comprehensive understanding of related equipment, staff's self-protection awareness is not strong, often brutal operation problems are caused by the accidents of mining machinery. Therefore, we must through training and education, and gradually strengthen the operator's responsibility and safety consciousness, safety operation key familiar with related equipment, it can improve the ability to control the equipment; must be in strict accordance with the rules of operation, to avoid psychological paralysis, only can reduce or eliminate equipment accident. In addition, the relevant management personnel of mining enterprises undue importance to maximize yield, one-sided pursuit of economic interests, the concept of security is weak, relevant personnel in the training is not comprehensive, resulting in some operators can better master the use of advanced equipment. 


\section{Countermeasures of Security Technology of Mining Machinery}

Improve Detection Technology. At present, many mechanical engineering experts are studying some new mechanical fault diagnosis theory and methods, such as the theory and method of wavelet packet transform and diagnosis model of artificial neural network method, virtual reality technology, nonlinear model theory and technology. Strengthening the research and application of the theory will greatly improve the safety of mining machinery. Large mining machinery, such as new, mining, mining and transportation equipment have completed the computer monitor; new type of electric traction shearer with intelligent monitoring, monitoring and protection system, can realize the distance detection and control, operating status display, fault identification and analysis; new tunneling machine can realize the direction detection, automatic electric power the cutting section of regulation, monitoring, condition monitoring and fault diagnosis and identification. Study on the method of accelerating mining machinery safety detection and fault diagnosis of the current mining machinery to large-scale development, intelligent and miniaturization direction, the development of theoretical research and practical application of the security problems related to many disciplines should strengthen the safety of mining machinery. Focus on basic safety design to deal with mining machinery, set up a set of safety of mining machinery principle and theory, the development needs of the use of mine machinery in China, to provide guidance for the design of mining machinery safety. Increase the research on the intrinsically safe design of mine gas, and establish a low cost and applicable design system of mine machinery safety. To eliminate the related risks in the design and improve the essential safety capability of the safety design of mine machinery.

Perfect Security Standards. The safety standards and safety technical regulations in the mining machinery related industries in industrialized countries provide the basis for establishing safety standards in our country. We should ensure that the safety standards established are in line with international standards and involve most of the equipment in the mining machinery. In addition, the state supervision organs should further strengthen their own law enforcement efforts to ensure the strict implementation of standards and regulations. Heavy duty, large scale, intelligent, high speed and miniaturization are the developing directions of mine machinery. Because its security involves many problems, it is difficult for the single theoretical subject to solve the problem, so it is necessary to establish a safety design system of mine machinery which adapts to the national conditions of our country. The safety design system should include theory, method and reason and so on. It is intended to provide correct guidance for mechanical safety design from the methodology point of view. The basic and common problems of mining machinery are studied, especially the research on flammable gas, and the establishment of mechanical safety database. In addition, we should start with the design link to reduce the risks involved in the safety design system, enhance its practicality, reduce its cost, and promote the effective improvement of its essential safety level. China's coal mining construction technology continues to make breakthroughs, and the difficulty and strength of coal mine construction are increasing. Mining machinery industry standard in our country should pay close attention to the development of chemical engineering machinery international safety standards, safety technical regulations and safety standards for timely tracking of heavy mining machinery in the advanced industrialized countries and related industries, increase the safety standards efforts, and actively develop safety standards with international standards, so that safety standards can cover the vast most of mining machinery products, supervision departments should also strengthen law enforcement, to ensure strict implementation of regulations and standards.

Strengthen Staff Training. The equipment in mine production has very strong technology. It requires the maintenance staff to have a high level of professional quality, familiar with the data of the normal operation of mechanical equipment in various production links, as well as various means of maintenance, accident elimination methods. In order to achieve safe and efficient in the production work, promote the establishment and implementation of China's machinery safety system, we must accelerate the training of technical personnel engaged in mining machinery safety design and research work, strengthen the selection and training of personnel and skilled workers, and comprehensively improve the level of technology and safety awareness of employees of mining 
machinery. With training institutions, teachers and teaching materials as the focus, we should continue to promote the standardization of coal mine safety training, and better improve the safety awareness and safety design technology level. Prior to the induction of staff, necessary skills training should be carried out. After examination, the personnel will be certified and the technical personnel recruitment system shall be standardized. At the same time, strictly implement the punishment and reward mechanism, improve the staff's attention to safety management, give severe punishment to the person who is responsible for the failure, and encourage the staff to do a good job in safety management. The development of science and technology, driven by the mining machinery equipment in China toward automated and semi-automated stride forward this form, put forward the relevant technical level and intelligence personnel higher and more stringent requirements. In order to promote the implementation of the safety system of mining machinery and realize efficient and safe production, it is necessary to start from the source and train a batch of scientific research and design personnel engaged in the safety of mining machinery. In addition, training and continuing education should be adopted to strengthen the safety awareness and technical level of skilled workers and operators. Considering the construction of personnel training system combining teaching materials, teachers and training institutions, we will realize standardized training and construction of mine safety, and further enhance the safety technical level and safety awareness of personnel.

\section{Conclusion}

Security technology of mine machinery safeguards the development of mining machinery industry. Only a high level of mining machinery safety technology can ensure the safety of the lives of practitioners and the country's property security. The development of security technology of mine machinery needs constant innovation. Under the encouragement of the national policy and the efforts of mining enterprises, we believe that in the near future, China's security technology of mining machinery will be upgraded qualitatively.

\section{References}

[1] Shao Kangning, Research on Data Encryption Technology in Computer Network Communication Security [J]. Cyberspace Security, 2016(2): 29-32.

[2] Wang Xiucui, The Application of the Data Encryption Technology in the Network Communication Security [J]. Software Guide, 2011, 10(3): 149-150.

[3] Yu Guangxu, Computer Network Security in the Use of Data Encryption Technology [J]. Computer Knowledge and Technology, 2013, 9(6): 1338-1339+1348.

[4] Zhang Tao, Application and Research of Transmission Encryption Technology of Wireless Network Data [J]. Wireless Internet Technology, 2015(19): 16-17. 